7. Reprod. Fert. (1967) 13, 41-50

\title{
DIFFERENCES OF FERTILITY IN RECIPROCAL CROSSES BETWEEN INBRED STRAINS OF MICE: DDK, KK AND NC
}

\author{
NOBORU WAKASUGI, TAKESHI TOMITA AND KYOJI KONDO
}

\author{
Department of Animal Breeding, Faculty of Agriculture, \\ Nagoya University, Nagoya, Japan
}

(Received 20th December 1965, revised 25th May 1966)

\begin{abstract}
Summary. A low fertility of DDK females mated to males from other inbred strains of mice, revealed in preliminary inter-strain crosses of several strains, was confirmed in a detailed study of strains DDK, KK and $\mathrm{NC}$, the nine possible matings being arranged. The mean litter sizes of four types of crosses, DDK females $\times \mathrm{KK}$ males, DDK females $\times \mathrm{NC}$ males, KK females $\times$ DDK males, and NC females $\times$ DDK males were $1 \cdot 1,2 \cdot 6,7 \cdot 2$ and $7 \cdot 7$ respectively. The mean litter sizes of the three inbred strains, $\mathrm{DDK}, \mathrm{KK}$ and $\mathrm{NC}$, were $5 \cdot 8,5 \cdot 6$ and $7 \cdot 0$ respectively.

The lowered fertility of DDK females mated to KK and NC males was accounted for by embryonic losses which occur about 3 to 4 days after copulation. The embryos die just before or in the process of implantation, i.e. before or during the process of blastocyst formation.

Probable causes of the embryonic losses in DDK females mated to KK and NC males are discussed.
\end{abstract}

\section{INTRODUCTION}

Genetical experiments have revealed a low fertility in certain crosses between inbred strains of mice, and one of the authors, T. Tomita, reported the phenomenon briefly at the meeting of the Genetic Society of Japan in 1960. When DDK females were mated with $\mathrm{KK}$ males, the average number of $\mathrm{F}_{1}$ young was $2 \cdot 2 \pm 0.5 /$ litter, but in the reciprocal cross, $\mathrm{KK}$ females produced $6 \cdot 7 \pm$ $0.8 \mathrm{~F}_{1}$ young/litter. Also more dead embryos were observed in the cross of DDK females with $\mathrm{KK}$ males than in the reciprocal mating. A similar reduction of litter size was observed in the cross between DDK and KSA. The sex ratio of the $F_{1}$ young from DDK females was normal. It was suggested that the semisterility in crosses involving DDK females might be caused by incompatibility between their egg cytoplasm and alien spermatozoa, or by some maternalembryonic interaction.

But, as no embryological observations had been carried out, many questions remain to be settled. Do DDK females always show a reduction of litter size when mated with males from other strains? How and when does the reduction of litter size occur, i.e. is the number of ova reduced, does fertilization happen 
normally, is cleavage and implantation normal or is development subsequently disturbed by a lethal gene?

The present paper is concerned with the developmental stage at which the reduction of litter size takes place in the crosses. The experiment was arranged in two parts, the first to confirm the reduction of fertility in DDK females mated to alien males; the second to identify the stage when the embryonic losses occur. The original observations were confirmed, and it has been shown that the embryonic loss occurs just before, or in the process of, implantation.

\section{MATERIAL AND METHODS}

The strains have been described by Kondo, Himeno, Ikoma \& Katsuragi (1953), and Kondo, Nozawa, Tomita \& Esaki (1957), and by Tajima (1963).

All mice were kept in wooden cages and fed with a commercial diet intended for chickens, approximately $5 \mathrm{~g} / \mathrm{head} / \mathrm{day}$. Water was available continuously. Room temperature was not controlled, but in winter heating was supplied to keep the temperature above $10^{\circ} \mathrm{C}$. The female mice used in the experiment were 2 to 5 months of age and the males used for mating were 3 to 7 months old. One male and one female were kept in a cage until the female showed a vaginal plug. The females were examined twice daily, between 09.00 and 10.00 hours and between 16.00 and 17.00 hours, and females with plugs were isolated into new cages and the time when the plug was found was scored as Hour 0 of embryonic development. Females which failed to show vaginal plugs within 1 week of mating were killed and their ovaries, oviducts and uteri examined. Diagnosis of pregnancy was made from the vaginal haemorrhage 13 days after copulation. Many of the pregnant females were dissected 14 days after coitus and the number of corpora lutea, implantation sites and live foetuses was recorded according to the method of Falconer \& Roberts (1960). The others were kept up to parturition to determine the litter size, which includes living and dead young.

Eggs and early embryos were observed in three stages: 30 to 34,54 to 58 and 74 to $78 \mathrm{hr}$ after copulation. In the first two stages, eggs were recovered by cutting the oviducts into short pieces in physiological saline under a binocular microscope (magnifications 5.6 to 90 ). In the third stage, eggs were similarly recovered from the uterus. The eggs were pipetted into a well slide, mounted under a cover slip sealed with petroleum jelly and observed under an ordinary or phase-contrast microscope. For more detailed examination, the eggs were stained according to the method of Sugawara \& Takeuchi (1962), i.e. with $0.04 \%$ nigrosin in physiological saline in a watch glass. After staining, the eggs were removed to pure physiological saline and examined under the microscope.

In order to study implantation and development, pregnant females were dissected at 4 to 9 days after coitus; this was done between 10.00 and 15.00 hours. Both uterine horns were removed, together with oviducts, ovaries and attached adipose tissue, and placed on a piece of filter paper in a petri dish. The ovaries were cut off and the number of corpora lutea was counted under a dissecting microscope to determine the number of eggs ovulated. The uteri were arranged on the filter paper and fixed in $10 \%$ formalin. After both horns had been separated and attached adipose tissue removed, they were transferred 
to Bouin's solution for histological study. Paraffin sections were made at $10 \mu$ and stained with Hansen's haematoxylin and eosin.

Intra-strain matings were observed in the same manner and used as control data. Litter size of the control series includes data from experimental and production colonies.

\section{RESULTS}

\section{Reproduction}

Preliminary experiments and the work of Tomita (1960) indicated that low fertility (reduction of litter size) occurs when DDK females are mated to alien males. The main part of the present experiment was designed to confirm this fact in the nine possible matings involving the DDK, $\mathrm{KK}$ and NC strains. $\mathrm{KK}$ and $N G$ were chosen because the origins of the strains are completely different and their reproductive behaviour and other characteristics are well known.

\section{TABLE 1}

PREGNANGY RATES IN NINE TYPES OF MATINGS InVOLVING THE DDK, KK aNd NG strains of MICE

\begin{tabular}{c|c|c|c}
\hline \multirow{2}{*}{ Females } & \multicolumn{3}{|c}{ Males } \\
\cline { 2 - 4 } & $D D K$ & $K K$ & $\mathcal{N} C$ \\
\hline \multirow{2}{*}{ DDK } & $28 / 35$ & $45 / 53$ & $49 / 58$ \\
& $(80 \cdot 0)$ & $(84 \cdot 9)$ & $(84 \cdot 5)$ \\
KK & $33 / 35$ & $19 / 20$ & $20 / 21$ \\
& $(94 \cdot 3)$ & $(95 \cdot 0)$ & $(95 \cdot 2)$ \\
NC & $61 / 67$ & $43 / 47$ & $21 / 21$ \\
& $(91 \cdot 0)$ & $(91 \cdot 5)$ & $(100)$ \\
\hline
\end{tabular}

28/35 stands for 'twenty-eight pregnant females out of a total of thirty-five females with vaginal plugs', or $80.0 \%$.

Pregnancy rates in the nine types of mating involving these three inbred strains are shown in Table 1. They are expressed as the proportion of pregnant females to females with vaginal plugs. The number of pregnant females included those with vaginal haemorrhage on the 13th day after coitus and females showing uterine swellings on dissection on Day 6. It is thought that the 13-day haemorrhage takes place not only with live embryos, but also with dead ones, even if represented by only a few embryonic cells. The pregnancy rates of DDK females were generally lower than those of other females. But the difference between DDK females mated to $\mathrm{KK}$ males and $\mathrm{KK}$ females mated to DDK males is comparatively slight and not statistically significant, and the same applies to the reciprocal crosses involving DDK and NC. Evidently there is little difference in pregnancy rates between reciprocal crosses.

Table 2 shows that females judged to be pregnant by the 13-day vaginal haemorrhage generally have living foetuses when dissected on the following day. However, DDK females mated to alien males behave differently. In the cross 
DDK female $\times \mathrm{KK}$ male, only $11 / 23$ or $47.8 \%$ of the pregnant females had living foetuses on Day 14, whereas in the reciprocal cross living foetuses were present in all fifteen females; the difference is highly significant $(P<0.001)$. A smaller and not significant difference in the same direction was present in the crosses involving DDK and NC. From the data in Tables 1 and 2, it may be

TABLE 2

PREGNANT FEMALES WITH LIVE FOETUSES ON DAY 14 OF PREGNANGY IN NINE TYPES OF MATINGS INVOLVING THREE INBRED STRAINS OF MICE

\begin{tabular}{c|c|c|c}
\hline \multirow{2}{*}{ Females } & \multicolumn{3}{|c}{ Males } \\
\cline { 2 - 4 } & $D D K$ & $K K$ & $\mathcal{N} C$ \\
\hline DDK & $16 / 16$ & $11 / 23^{*}$ & $16 / 18$ \\
& $(100)$ & $(47 \cdot 8)$ & $(88 \cdot 9)$ \\
KK & $15 / 15$ & $9 / 9$ & $8 / 8$ \\
& $(100)$ & $(100)$ & $(100)$ \\
NC & $24 / 25$ & $22 / 22$ & $10 / 10$ \\
& $(96.0)$ & $(100)$ & $(100)$ \\
\hline
\end{tabular}

* 11/23 indicates that eleven out of twenty-three pregnant females had live foetuses when dissected on Day 14, with percentage in parentheses. The low value of $47.8 \%$ is significantly different from the reciprocal $(P<0.001)$.

\section{TABLE 3}

PREGNANT FEMALES WHICH GAVE BIRTH TO LIVING YOUNG IN NINE TYPES OF MATINGS INVOLVING THREE INBRED STRAINS OF MICE

\begin{tabular}{c|c|c|c}
\hline \multirow{2}{*}{ Females } & \multicolumn{3}{|c}{ Males } \\
\cline { 2 - 4 } & $D D K$ & $K K$ & $\mathcal{N} C$ \\
\hline \multirow{2}{*}{ DDK } & $10 / 10$ & $8 / 17^{*}$ & $14 / 17$ \\
& $(100)$ & $(47 \cdot 1)$ & $(82 \cdot 4)$ \\
KK & $15 / 15$ & $9 / 9$ & $11 / 11$ \\
& $(100)$ & $(100)$ & $(100)$ \\
NC & $33 / 33$ & $21 / 21$ & $10 / 10$ \\
& $(100)$ & $(100)$ & $(100)$ \\
\hline
\end{tabular}

* 8/17 indicates that eight out of seventeen pregnant females, or $47.1 \%$, gave birth to living young. The low value of $47.1 \%$ is significantly different from the reciprocal $(P<0.01)$.

concluded that mating between DDK females and alien males happens regularly and is followed by pregnancy; but that about one-half of the DDK females mated to KK males lose their embryos by the 14th day, and that the same happens (though without statistical significance) to about $10 \%$ of DDK females mated to NC males.

This conclusion is confirmed by the proportion of pregnant females which 
give birth to living young (Table 3 ): for the cross DDK female $\times \mathrm{KK}$ male, that proportion is $47.1 \%$, for the cross DDK female $\times$ NC male it is $82.4 \%$. For the remaining seven mating types, all pregnant females produced living offspring. Comparison between the figures in Tables 2 and 3 suggests that embryonic losses were rare after Day 14 of pregnancy.

The nature of the embryonic losses is further clarified by comparison of the number of corpora lutea, of implantations and living foetuses on Day 14 of pregnancy and litter size at birth. The data are presented in Table 4. In the semi-sterile crosses (DDK females $\times \mathrm{KK}$ males, and DDK females $\times$ NC males), the number of corpora lutea (= eggs ovulated) was not reduced, but the number of implantations was smaller than normal, and the number of living foetuses and of young born were greatly reduced. Evidently, ovulation is normal

TABLE 4

MEAN AND ITS 95\% CONFIDENCE LIMIT FOR NUMBERS OF CORPORA LUTEA, IMPLANTS, LIVE FOETUSES (14 DAYS AFTER COPULATION) AND LITTER SIZE (AT BIRTH) PER PREGNANT FEMALE IN NINE TYPES OF CROSSES INVOLVING THREE INBRED STRAINS OF MICE

\begin{tabular}{|c|c|c|c|c|}
\hline $\begin{array}{l}\text { Types of } \\
\text { crosses }\end{array}$ & $\begin{array}{l}\text { No. of } \\
\text { corpora lutea }\end{array}$ & $\begin{array}{l}\text { No. of } \\
\text { implants }\end{array}$ & $\begin{array}{l}\text { No. of } \\
\text { live foetuses }\end{array}$ & $\begin{array}{l}\text { Litter } \\
\text { size }\end{array}$ \\
\hline $\begin{array}{c}\text { Female } \text { Male } \\
\text { DDK } \times \text { DDK }\end{array}$ & $10 \cdot 8 \pm 0 \cdot 9(16)$ & $8 \cdot 7 \pm 1 \cdot 1(16)$ & $7 \cdot 9 \pm 1 \cdot 1(16)$ & $5 \cdot 8 \pm 0 \cdot 4(75)$ \\
\hline $\mathrm{DDK} \times \mathrm{KK}$ & $9.9 \pm 0.6(23)$ & $4 \cdot 7 \pm 1 \cdot 0(23)$ & $1 \cdot 0_{ \pm 0}^{* * *}(23)$ & $1 \cdot 1^{*} \pm 0 \cdot 6(17)$ \\
\hline $\mathrm{DDK} \times \mathrm{NC}$ & $9 \cdot 7 \pm 0 \cdot 6(18)$ & $5 \cdot 4 \pm 1 \cdot 0(18)$ & $2 \cdot 8_{ \pm}^{* *} 1.0(18)$ & $2 \cdot 6 \pm 0.9(17)$ \\
\hline $\begin{array}{l}\mathrm{KK} \times \mathrm{DDK} \\
\mathrm{KK} \times \mathrm{KK} \\
\mathrm{KK} \times \mathrm{NC}\end{array}$ & $\begin{array}{l}10.8 \pm 1.0(15) \\
12.3 \pm 1.5(9) \\
11.3 \pm 1.5(8)\end{array}$ & $\begin{array}{l}8 \cdot 6 \pm 1 \cdot 2(15) \\
9 \cdot 7 \pm 0.9(9) \\
9 \cdot 3 \pm 1 \cdot 0(8)\end{array}$ & $\begin{array}{l}7.4 \pm 1 \cdot 0(15) \\
8 \cdot 6 \pm 0.6(9) \\
8 \cdot 0 \pm 1.9(8)\end{array}$ & $\begin{array}{l}7 \cdot 2 \pm 1 \cdot 0(14) \\
5 \cdot 6 \pm 0 \cdot 5(85) \\
6 \cdot 3 \pm 0 \cdot 8(11)\end{array}$ \\
\hline $\begin{array}{l}\mathrm{NG} \times \mathrm{DDK} \\
\mathrm{NG} \times \mathrm{KK} \\
\mathrm{NG} \times \mathrm{NC}\end{array}$ & $\begin{array}{l}12.6 \pm 1.0(25) \\
11.8 \pm 0.6(22) \\
12.7 \pm 1.5(10)\end{array}$ & $\begin{array}{l}9 \cdot 8 \pm 1 \cdot 1(25) \\
9 \cdot 3 \pm 0 \cdot 9(22) \\
9 \cdot 4 \pm 2 \cdot 0(10)\end{array}$ & $\begin{array}{l}8 \cdot 4 \pm 1 \cdot 3(25) \\
7 \cdot 7 \pm 1 \cdot 0(22) \\
8 \cdot 3 \pm 2 \cdot 3(10)\end{array}$ & $\begin{array}{l}7.7 \pm 0.8(33) \\
8.1 \pm 0.9(21) \\
7.0 \pm 0.6(75)\end{array}$ \\
\hline
\end{tabular}

Asterisks indicate the significances of differences compared with the intra-strain cross of DDK $\left(* * * P<0.01,{ }^{* *} P<0.02,{ }^{*} P<0.05\right)$.

Numbers of females used are shown in parentheses.

even in the sterile crosses, and litter size is reduced during development. The sex ratio of the young from DDK females mated to $\mathrm{KK}$ and $\mathrm{NG}$ males was 7 males : 10 females and 25 males : 20 females respectively; embryonic mortality is thus apparently not influenced by sex, as observed previously in 1960 . The implantation sites where embryonic death had occurred were recognizable, and the placental remnant was usually less than $3 \mathrm{~mm}$ in diameter; they were thus 'moles' in the sense of Edwards \& Fowler (1959) which means that death in the sterile crosses tends to occur before Day 9 of pregnancy.

It may be concluded that DDK females show a reduction of litter size (though to a varying extent) when mated to males from other strains. Furthermore, it may be supposed that embryonic loss occurs before and/or around the stage of implantation. 
Eggs and early embryos

To identify the critical stage when the embryonic losses occur in DDK females mated to $\mathrm{KK}$ and NG males, the number of normal and abnormal embryos was determined (Text-figs. 1 and 2). The control results (DDK

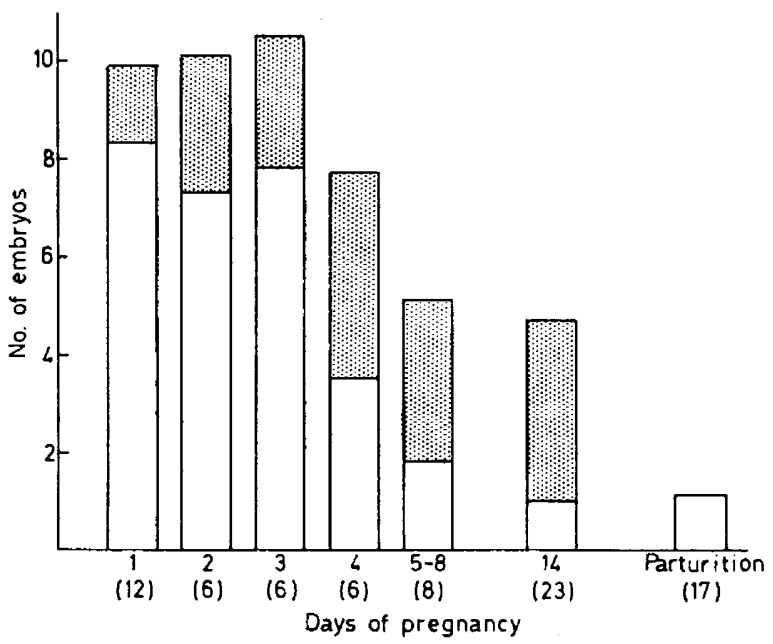

Text-Fig. 1. The mean numbers of normal and abnormal embryos in the cross of DDK females $\times$ KK males. Numbers in parentheses indicate the numbers of females examined. Hatched areas represent abnormal embryos, the remaining areas showing normal embryos. Standard errors from left to right are: normal embryos, $0 \cdot 5,1 \cdot 0,1 \cdot 0,1 \cdot 1,0 \cdot 6$, $0 \cdot 3,0 \cdot 3$ : abnormal embryos, $0 \cdot 7,0.6,1 \cdot 0,0.9,0.4,0.4,-$. Day 1 is defined as 30 to $34 \mathrm{hr}$, Day 2 as 54 to $58 \mathrm{hr}$, Day 3 as 78 to $82 \mathrm{hr}$.

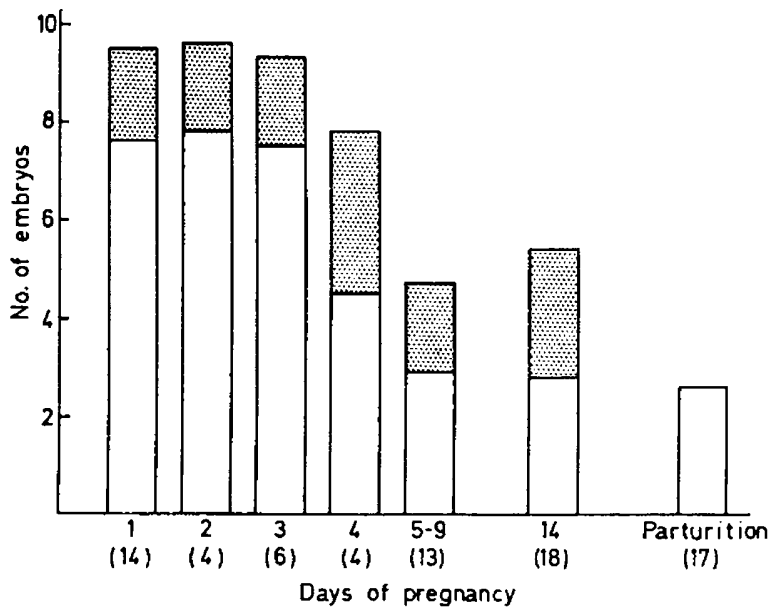

TEXT-FIG. 2. The mean numbers of normal and abnormal embryos in the cross of DDK females $\times$ NC males. Standard errors from left to right are: normal embryos, $0.7,1 \cdot 4$, $0.6,0.6,0.4,0.5,0.4$; abnormal embryos, $0.7,0.6,0.7,1.5,0.5,0.2,-$. Remainder of legend as in Text-fig. 1 .

females $\times$ DDK males; KK females $\times$ DDK males; and $N G$ females $\times$ DDK males) were consistent and have been pooled in Text-fig. 3 .

At 30 to $34 \mathrm{hr}$ after coitus, 2-cell stages were classified as normal; abnormal eggs are either uncleaved or of irregular shape. There was no significant differ- 
ence in number of normal and abnormal eggs between sterile and control data. As all the 2-cell eggs had extruded the second polar body, fertilization must have happened normally as also deduced from Tables 1 and 2. Evidently, the eggs of DDK females are fertilized in normal numbers by the spermatozoa of KK and NG males and proceed to early cleavage.

At 54 to $58 \mathrm{hr}$ or 2 days after copulation, 4-cell eggs were counted as normal and all other irregular types as abnormal. The number of abnormal embryos at this stage increased slightly in the cross of DDK females and $\mathrm{KK}$ males as compared with the controls, but not in the cross DDK females $\times \mathrm{NC}$ males.

Fertile eggs usually develop to the morula stage in 3 days or 78 to $82 \mathrm{hr}$ after copulation (Pl. 1, Fig. 1). Hence the morula at this stage was classified as normal, and less advanced or irregular embryos as abnormal. There was no great difference in number of normal and abnormal embryos between the sterile

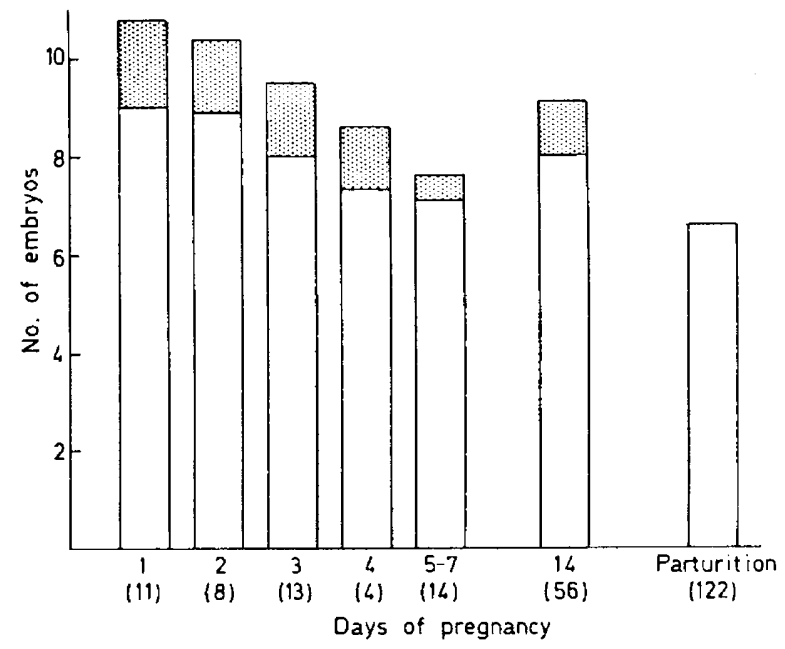

TexT-Fig. 3. The mean numbers of normal and abnormal embryos in the pooled control matings. Standard errors from left to right are: normal embryos, $0 \cdot 4,0 \cdot 8,0 \cdot 2,0 \cdot 6,0 \cdot 5$, $0.3,0.2$; abnormal embryos, $0.5,0.4,0.3,0.5,0.2,0.1,-$. Remainder of legend as in Text-fig. 1 .

crosses and the controls. But it is worth noting that some of the apparently normal morulae, in all crosses, stained partially with nigrosin (PI. 1, Fig. 2). Although the use of nigrosin staining for the discrimination of live and dead morulae is not well established, it may be considered that partial staining may be a sign of degeneration. And more stainable morulae were found in the sterile than in the normal crosses.

At 4 days of pregnancy, the number of abnormal embryos has increased and that of normal embryos decreased considerably in the sterile crosses. Embryonic death thus begins to occur at this stage in matings of DDK females with $\mathrm{KK}$ and NC males. The normal embryo, at this stage, has developed beyond the blastocyst stage, and those which had remained in the morula stage were regarded as abnormal. In the normal crosses or in the controls, classification was easy, but in the sterile crosses there were all kinds of intergrades in the embryos (Pl. 1, Figs. 3 to 6). Thereafter, it was difficult to classify them in two 
classes, normal and degenerated. In the sterile crosses (Text-figs. 1 and 2), all embryos which had a blastocoele were counted as normal (such as that shown in Pl. 1, Fig. 4). Consequently, the 'normals' in these crosses include many embryos of less advanced developmental stages, and about one-half of them were probably degenerating. In all crosses, the total number of embryos (normal+ abnormal) was reduced between 3 and 4 days of pregnancy (Pl. l, Figs. 1 to 3 ). As, in normal development, the zona pellucida has disappeared during these stages, it is supposed that those embryos, which were counted as abnormal before 3 days of gestation, may disappear and thus will not be counted at 4 days after coitus.

At 5 days of gestation, the classification of normal and abnormal (or moribund) embryos became clear, and later than 5 days the classification was also clear, even in the sterile crosses; i.e. embryos were classified as normal or abnormal depending on whether they had reached the embryonic organization appropriate to their age or had failed to do so. Normal and abnormal embryos at 5 days after copulation are shown in Pl. 2, Figs. 7 to 10. After 6 days of pregnancy, it was usually difficult to identify dead embryos with the naked eye, but in some cases a few cells derived from degenerated embryos were found histologically. However, as the decidua was thickened even though the embryo was dead, as seen in Pl. 2, Fig. 11, and as the placental remnant was seen clearly at 14 days of gestation, it was possible to count the number of degenerated embryos.

Probably, embryonic death after 5 days of pregnancy is rare, and most deaths may take place by 4 days of pregnancy in DDK females mated with KK and NG males. If so, then the critical period must be at 3 to 4 days of pregnancy, i.e. just before implantation or in the process of implantation.

The main criterion for judging an embryo to be abnormal was that body size was smaller than in sibs or in control groups.

\section{DISCUSSION}

The results of the present study confirm the previous observations reported by Tomita in 1960 that DDK females crossed to alien males are semi-sterile. Moreover, it has been confirmed that the death of the embryos occurs before implantation or during the process of implantation. By contrast, $\mathrm{KK}$ and NG females mated to DDK males produced slightly more young than intra-strain matings.

Many questions arise from the present study. It is clear that lethal genes are not responsible for the death of the embryos. All three strains used in this study have been maintained by brother-sister matings for over forty generations, and it is thus highly unlikely that they could harbour systems of lethal genes: the fact that all of them, in intra-strain matings, have litters of normal size is clear evidence that in fact no such genes are present. The normal sex ratio of young of DDK females mated to alien males in any case excludes the operation of sex-linked lethals.

Though the cause of embryonic death remains to be discovered, the case will be discussed in relation to comparable instances in other animals. Laven (1957) 


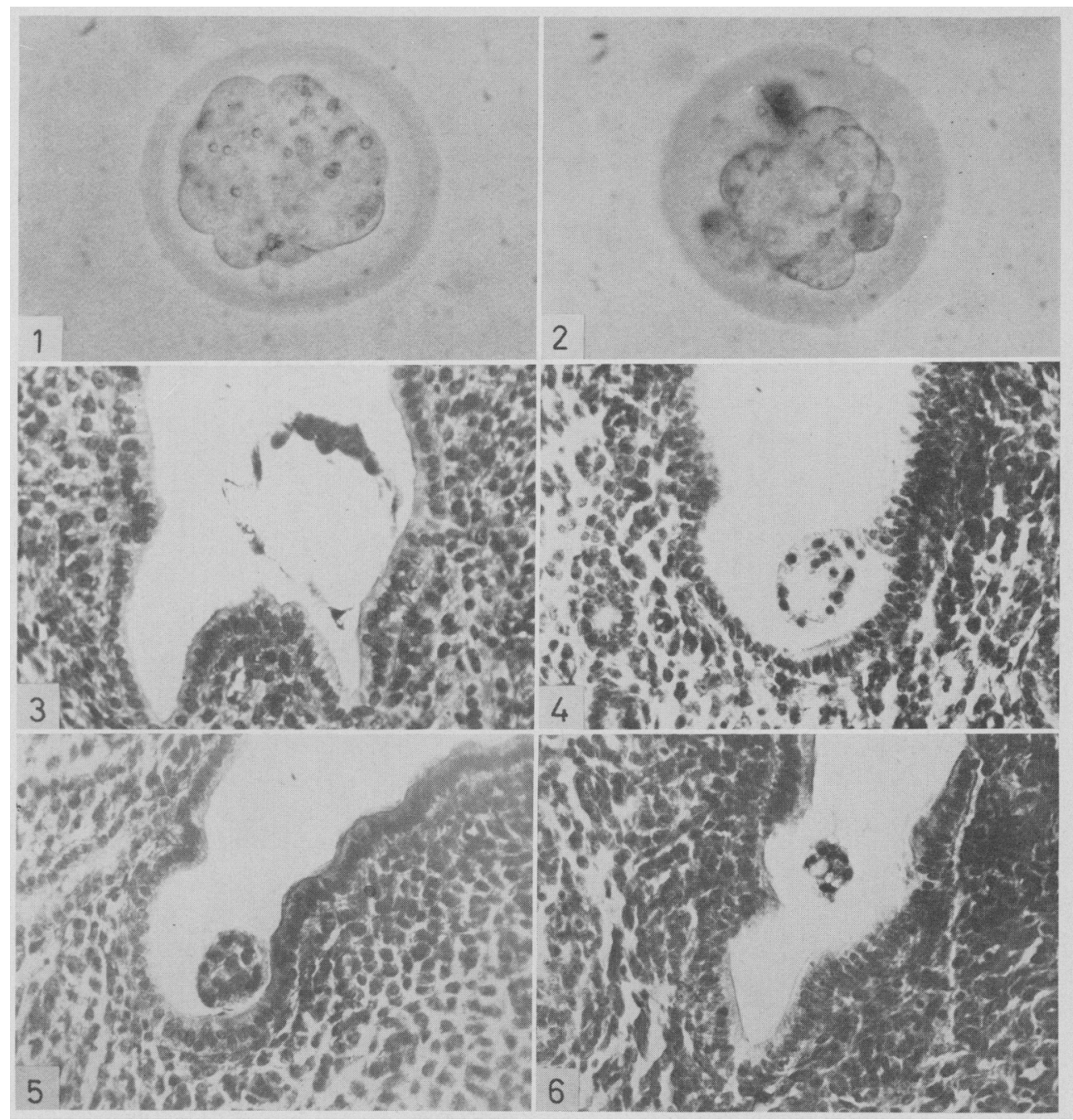

Fis. 1. Normal morula at 78 to $82 \mathrm{hr}$ (not stained by nigrosin).

lis i. 2. Abnormal morula at 78 to $82 \mathrm{hr}$ from the cross of DDK females $\times \mathrm{KK}$ males (partially stained by nigrosin).

Fifi. 3. Four-day cmbryo from DDK females $\times$ DDK males mating (trophoblast developed normally).

FI';. 4. Four-day embryo from DDK females $\times \mathrm{NC}$ males mating (trophoblast poorly developed).

Firi. 5. Four-day embryo from DDK fenales $\times \mathrm{NC}$ males mating which has remained in the morula stage.

lirs. 6. Degenerating 4-day embryo from mating DDK females $\times \mathrm{KK}$ males.

(Facing p. 48) 

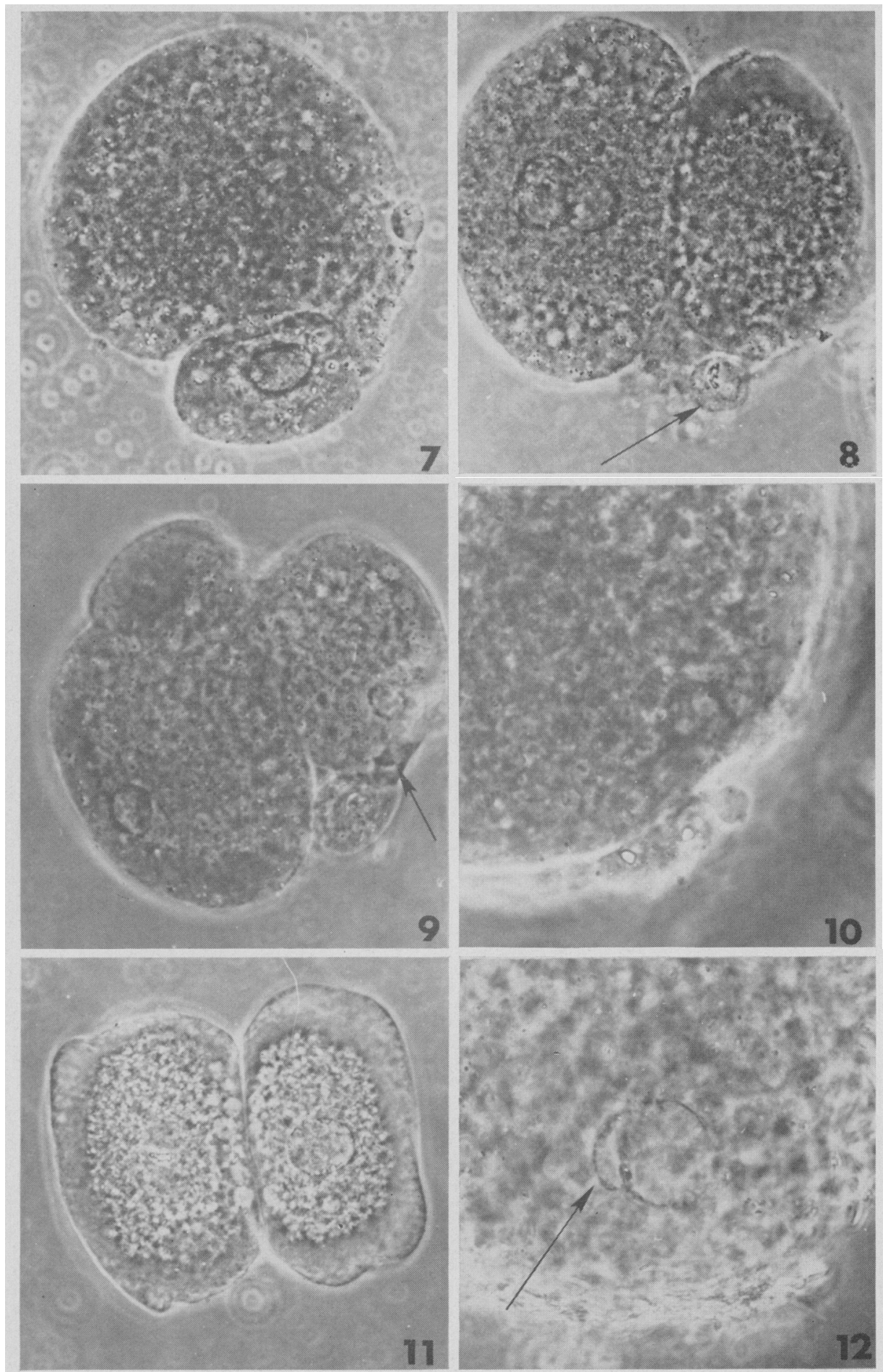


\section{PLATE 1}

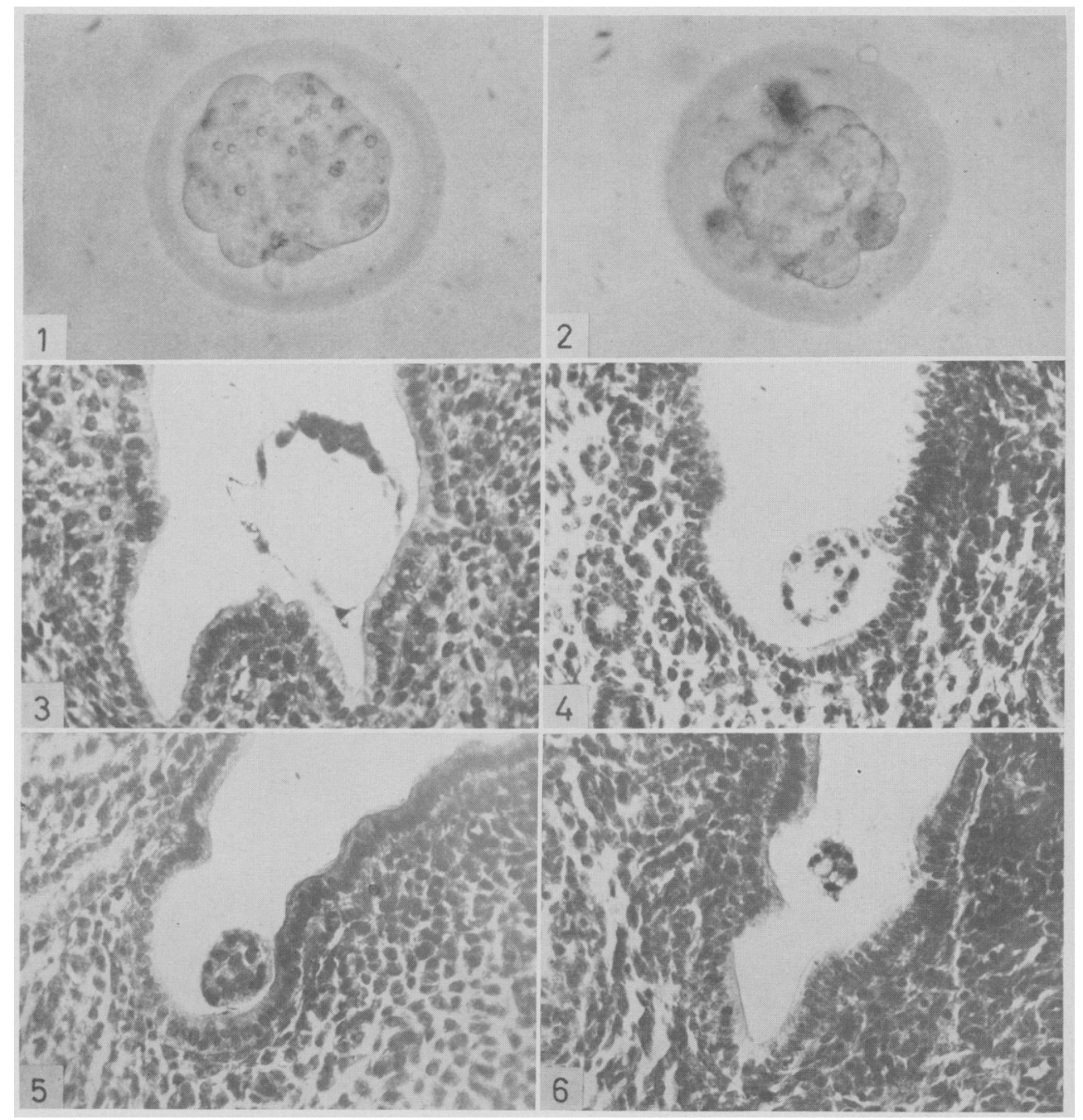

Fig. 1. Normal morula at 78 to $82 \mathrm{hr}$ (not stained by nigrosin).

FIG. 2. Abnormal morula at 78 to $82 \mathrm{hr}$ from the cross of DDK females $\times \mathrm{KK}$ males (partially stained by nigrosin).

Fic. 3. Four-day embryo from DDK females $\times$ DDK males mating (trophoblast developed normally).

FIG. 4. Four-day embryo from DDK females $\times$ NC males mating (trophoblast poorly developed).

Fig. 5. Four-day embryo from DDK females $\times$ NG males mating which has remained in the morula stage.

FIG. 6. Degenerating 4-day embryo from mating DDK females $\times \mathrm{KK}$ males. 


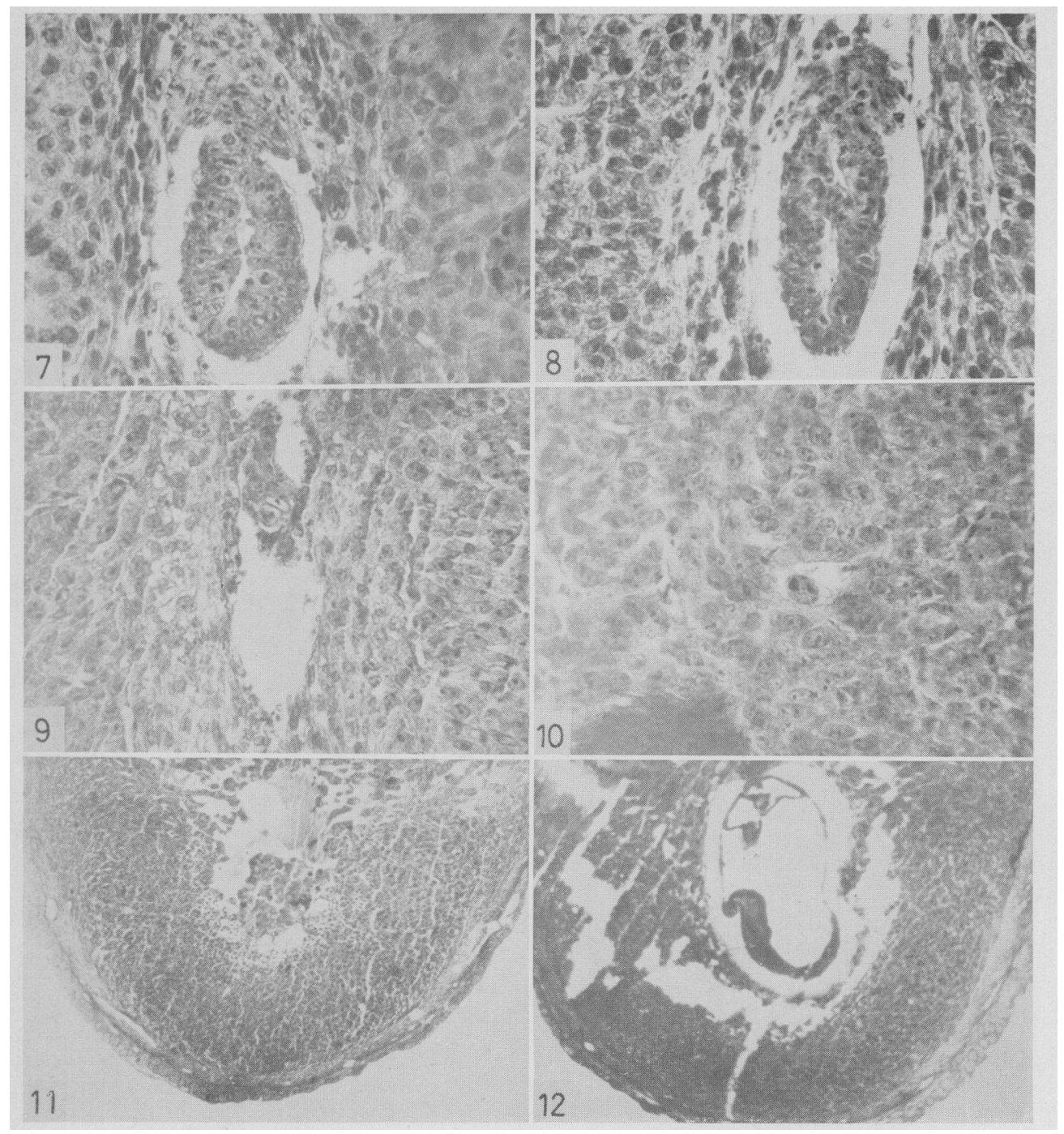

Firs. 7 and 8. Nornial 5-day embryos at early egg cylinder stage.

Fic. 9. Degenerated 5-day (mbryo from DDK females $\times \mathrm{KK}$ males mating.

FIG. 10. Degenerated 5-day embryo from DDK females $\times \mathrm{NC}$ males cross. Only a single enbryonic cell remains.

FIG. 11. Implantation site with dead and degenerated embryo (7 days after copulation) from $\mathrm{DDK}$ females $\times \mathrm{KK}$ males mating.

FIG. 12. Normal 8-day embryo from DDK females $\times$ NC males cross. 
reported that in reciprocal crosses between two strains of mosquitoes, that of $\mathrm{Ha}$ female to $\mathrm{Og}$ male was fertile, but in the reciprocal cross the offspring died as embryos. The $\mathrm{Og}$ genome was transferred into $\mathrm{Ha}$ cytoplasm by fifty-two successive back-crosses of ( $\mathrm{Ha}$ female $\times \mathrm{Og}$ male) hybrids to $\mathrm{Og}$ males; the males thus obtained did not produce any offspring when mated to Og females. Accordingly, Laven suggested that incompatibility between the cytoplasm of the $\mathrm{Og}$ ovum and the cytoplasmic component of $\mathrm{Ha}$ spermatozoa may be the cause of this embryonic death. A similar mechanism might be operative in the present case.

Embryonic death, in DDK females mated to alien males, occurs in or around the blastocyst stage when embryos begin to absorb actively metabolites from outside to initiate visible morphogenesis. Sugawara \& Umezu (1961) studied the metabolism of rat ova in vitro and observed that, following a linear increase in oxygen consumption from the 1-cell to the 4-cell stage, a non-linear and drastic increase takes place in the blastocyst stage, particularly in the presence of glucose or serum as substrates. Smith (1956) observed that $t^{12} / t^{12}$ mouse embryos die before blastocyst formation; there is little cytoplasmic RNA and the nucleoli fail to undergo changes typical of the normal embryo. The author discussed the possibility that failure of organization in these embryos might be caused by the production of an antimetabolite. Mintz (1964) observed that these embryos in vitro failed to incorporate ${ }^{3} \mathrm{H}$-uridine into nucleolar RNA as compared with the normal morula. However, when incubation was prolonged or at relatively high concentration of ${ }^{3} \mathrm{H}$-uridine, mutant nucleoli incorporated substantial amounts of the label into RNA. Cytoplasmic incorporation, however, was slight under the same incubating conditions. The author suggested that impairment of some necessary transport mechanism might be responsible.

The present results could also be interpreted on the assumption that, at the stage when the embryos begin active metabolism, an incompatibility between the nucleus (which has $\mathrm{F}_{1}$ constitution) and the cytoplasm (which is derived from the DDK mother) might interfere with some metabolic process. However, this does not account for the fact that some healthy young are born of these matings.

Robertson (1942), using an ovarian transplantation technique, observed that $A^{y} \mid A^{y}$ mouse embryos developed further in the uterus of an $A / A$ than in that of an $A^{y} / A$ female. In the uterus of the former, $A^{y} / A^{y}$ embryos developed a small ectoplacental cone and Reichert's membrane whereas in the uterus of an $A^{y} / A$ female there was no development of a trophectoderm, no blastocyst cavity and no differentiation into ectodermal and endodermal germ layers. However, non- $A^{y} / A^{y}$ embryos can develop normally even in $A^{y} / A$ mothers. It may be suggested that perhaps the uterine conditions of DDK females are unfavourable for the development of $F_{1}$ embryos, but have no such effect on DDK embryos. Such conditions unfavourable for $F_{1}$ embryos may last for a relatively short time and interfere with a single specific process. For instance, if $F_{1}$ embryos in a DDK uterus have difficulties with trophoblast formation, they will tend to die at that stage; but embryos will vary, and some will pass through this critical period, continue subsequent development and survive to birth. Such fortunate 
young are few in number, but they show no sign of malformation and no pathological symptoms.

The fact that $\mathrm{DDK} / \mathrm{KK}$ embryos suffer more from whatever is responsible for embryonic death than DDK/NG embryos is obviously an expression of the genetic difference between these two $F_{1}$ types.

Future work will be needed to reveal the actual cause of embryonic death and to clarify the mechanism(s) through which the death of the embryos occurs.

\section{ACKNOWLEDGMENTS}

The authors wish to thank Dr S. Sugawara, Tohoku University, Japan, for advice on the handling of mouse eggs. They are also grateful to Professor $\mathrm{H}$. Grüneberg (University College London) for preparing the original manuscript of this paper for the press and for useful suggestions. Thanks are also due to the Lederle Laboratories, New York, U.S.A., for financial assistance.

\section{REFERENCES}

Edwards, R. G. \& Fowler, R. E. (1959) Fetal mortality in adult mice after superovulation with gonadotrophins. F. exp. Zool. 141, 299.

FalCONER, D. S. \& RoberTs, R. C. (1960) Effect of inbreeding on ovulation rate and foetal mortality in mice. Genet. Res. 1, 422.

Kondo, K., Himeno, K., Ikoma, H. \& Katsuragi, T. (1953) The breeding in mouse. [Japanese with English summary]. Bull. natn. Inst. agric. Sci., Tokyo, ser. G (Anim. Husb. Tokyo), No. 7, 9.

Kondo, K., Nozawa, K., Tomita, T. \& Esaki, K. (1957) On the origins and characteristics of inbred strains of mice established in Japan. [In Japanese]. Bull. exp. Anim. Tokyo, 6, 107.

Laven, H. (1957) Vererbung durch Kerngene und das Problem der ausserkaryotischen Vererbung bei Culex pipiens. 2. Ausserkaryotische Vererbung. Z. indukt. Abstamm.- u. VererbLehre, 88, 478.

Mintz, B. (1964) Synthetic processes and early development in the mammalian egg. F. exp. Zool. 157, 85.

Robertson, G. G. (1942) An analysis of the development of homozygous yellow mouse embryos. 7. exp. Zool. 89, 197.

Sмrтн, L. J. (1956) A morphological and histochemical investigation of a preimplantational lethal $\left(t^{12}\right)$ in the house mouse. 7. exp. Zool. 132, 51.

Sugawara, S. \& UMezu, M. (1961) Studies on the metabolism of the mammalian ova. 2. Oxygen consumption of the cleaved ova of the rat. Tohoku F. agric. Res. 12, 17.

Sugawara, S. \& TAKEUchi, S. (1962) On the relationship between the staining affinity and respiratory activity of the rat ova. [In Japanese]. Fap. F. Anim. Reprod. 8, 77.

TAJima, Y. (1963) Laboratory animals in Japan, species and strains (or lines) of laboratory animals maintained in Japan. [In Japanese]. Bull. exp. Anim. Tokyo, 12, 145.

TомiтA, T. (1960) One-side cross sterility between inbred strains of mice. [In Japanese]. (Abstract). Jap. F. Genet. 35, 291. 